JOURNAL OF ENGINEERING SCIENCES

Volume 7, Issue 2 (2020)

Kanagasabai L. (2020). Real power loss reduction by Rock Dove optimization and Fuligo Septica optimization algorithms. Journal of Engineering Sciences, Vol. 7(2), pp. E1-E6, doi: 10.21272/jes.2020.7(2).e1

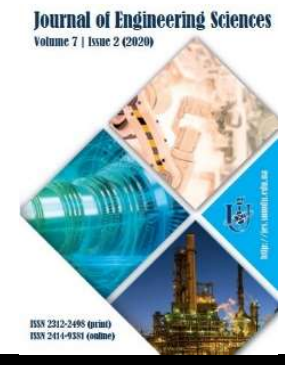

\title{
Real Power Loss Reduction by Rock Dove Optimization and Fuligo Septica Optimization Algorithms
}

\author{
Kanagasabai L. \\ Department of EEE, Prasad V. Potluri Siddhartha Institute of Technology, Kanuru, Vijayawada, 520007, Andhra Pradesh, India
}

\author{
Article info: \\ Paper received: \\ The final version of the paper received \\ Paper accepted online:
}

\author{
May 10,2020 \\ October 3, 2020 \\ October 23, 2020
}

*Corresponding email:

gklenin@gmail.com

\begin{abstract}
This paper aims to use the Rock Dove (RD) optimization algorithm and the Fuligo Septica optimization (FSO) algorithm for power loss reduction. Rock Dove towards a particular place is based on the familiar (sight) objects on the traveling directions. In the formulation of the RD algorithm, atlas and range operator, and familiar sight operators have been defined and modeled. Every generation number of Rock Dove is reduced to half in the familiar sight operator and Rock Dove segment, which hold the low fitness value that occupying the lower half of the generation will be discarded. Because it is implicit that individual's Rock Dove is unknown with familiar sights and very far from the destination place, a few Rock Doves will be at the center of the iteration. Each Rock Dove can fly towards the final target place. Then in this work, the FSO algorithm is designed for real power loss reduction. The natural vacillation mode of Fuligo Septica has been imitated to develop the algorithm. Fuligo Septica connects the food through swinging action and possesses exploration and exploitation capabilities. Fuligo Septica naturally lives in chilly and moist conditions. Mainly the organic matter in the Fuligo Septica will search for the food and enzymes formed will digest the food. In the movement of Fuligo Septica it will spread like a venous network, and cytoplasm will flow inside the Fuligo Septica in all ends. THE proposed RD optimization algorithm and FSO algorithm have been tested in IEEE 14, 30, 57, 118 and 300 bus test systems and simulation results show the projected RD and FSO algorithm reduced the real power loss.
\end{abstract}

Keywords: optimal reactive power, transmission loss, Rock Dove, Fuligo Septica.

\section{Introduction}

Reactive power problem plays an important role in secure and economic operations of power system. Numerous types of methods [1-6] have been utilized to solve the optimal reactive power problem. However, many scientific difficulties are found while solving problem due to an assortment of constraints. Evolutionary techniques [7-17] are applied to solve the reactive power and optimization problems. This paper proposes Rock Dove (RD) optimization algorithm and Fuligo Septica Optimization (FSO) algorithm for real power loss reduction. Proposed RD algorithm based on the natural behavior of Rock Dove. Normally Rock Dove locates the home and place by sun, familiar sight objects and magnetic field. Through the nose they magnetic particles are reaching to the brain in the part of trigeminal nerve. Rock dove uses many tools to identify the diverse path. In the proposed work atlas and range operator along with familiar sight operator has been defined and modelled. Each Rock
Dove explore through the solution space by varying its flight based on its own individual most excellent position. Rock Dove moves towards global best path by the evaluation of the paths. Procedure of discover the solution space is repetitive until the utmost iterations reached. Based on their fitness value Center of the Rock Dove raking is done. Lowest fitness value possessed Rock Dove will move towards those Rock Dove which has highest fitness values. This will diversify the solution space and thus avert the premature convergence. Then in this work Fuligo Septica Optimization (FSO) algorithm is designed for real power loss reduction. Natural vacillation mode of Fuligo Septica has been imitated to design the algorithm. Solid veins form generally beside the radius when the retrenchment frequencies diverge from exterior to within. Once the retrenchment mode is unbalanced, anisotropy commences to materialize. Once the retrenchment model of Fuligo Septica is not prearranged with time and space, then the venous formation will not exist. Consequently, the association between venous formation and retrenchment 
model of Fuligo Septica is constant with the outline of in nature produced cells. The depth of each vein is defined by the flow feedback of the cytoplasm. Veins diameter increased by the flow of cytoplasm. When flow decrease, the veins diameter decreases. Proposed Rock Dove (RD) optimization algorithm and Fuligo Septica Optimization (FSO) algorithm has been tested in standard IEEE 14, 30, 57,118 and 300 bus test systems and simulation results show the projected RD and FSO algorithm reduced the real power loss efficiently.

\section{Research Methodology}

\subsection{Problem formulation} loss:

Objective of the problem is to reduce the true power

$$
F=P_{L}=\sum_{k \in N b r} g_{k}\left(V_{i}^{2}+V_{j}^{2}-2 V_{i} V_{j} \cos \theta_{i j}\right)
$$

Voltage deviation is given as follows:

$$
\mathrm{F}=\mathrm{P}_{\mathrm{L}}+\omega_{\mathrm{v}} \times \text { Voltage Deviation. }
$$

Voltage deviation given by:

$$
\text { Voltage Deviation }=\sum_{i=1}^{N p q}\left|V_{i}-1\right| \text {. }
$$

Constraint (equality):

$$
\mathrm{P}_{\mathrm{G}}=\mathrm{P}_{\mathrm{D}}+\mathrm{P}_{\mathrm{L}}
$$

Constraints (inequalities):

$$
\begin{gathered}
\mathrm{P}_{\text {gslack }}^{\min } \leq \mathrm{P}_{\text {gslack }} \leq \mathrm{P}_{\text {gslack }}^{\max } \\
\mathrm{Q}_{\mathrm{gi}}^{\min } \leq \mathrm{Q}_{\mathrm{gi}} \leq \mathrm{Q}_{\mathrm{gi}}^{\max }, \mathrm{i} \in \mathrm{N}_{\mathrm{g}} \\
\mathrm{V}_{\mathrm{i}}^{\min } \leq \mathrm{V}_{\mathrm{i}} \leq \mathrm{V}_{\mathrm{i}}^{\max }, \mathrm{i} \in \mathrm{N}_{\mathrm{b}} \\
\mathrm{T}_{\mathrm{i}}^{\min } \leq \mathrm{T}_{\mathrm{i}} \leq \mathrm{T}_{\mathrm{i}}^{\max }, \mathrm{i} \in \mathrm{N}_{\mathrm{T}} \\
\mathrm{Q}_{\mathrm{c}}^{\min } \leq \mathrm{Q}_{\mathrm{c}} \leq \mathrm{Q}_{\mathrm{C}}^{\max }, \mathrm{i} \in \mathrm{N}_{\mathrm{C}} .
\end{gathered}
$$

\subsection{Rock Dove optimization algorithm}

Rock Dove (RD) optimization algorithm is defined and designed for real power loss reduction in this work. The natural actions of Rock Dove have been imitated to model the algorithm. Many researchers revealed that movement of the Rock Dove towards a particular place is based on the familiar (sight) objects on the traveling directions. In the formulation of the algorithm, atlas and range operators, and familiar sight operator have been defined and modeled.

In the movement of Rock Dove the conception of atlas and range operator along with familiar sight operator will assist the Rock Dove to find the direction and position.

$$
\begin{aligned}
& \text { Velocity }_{i}(t)=\text { Velocity }_{i}(t-1) \cdot e^{\text {art }}+\text { random } * \\
& *\left(Y_{\text {current best position }}-Y_{\text {New position }}(t-1)\right) \text {; } \\
& Y_{\text {New position }}=Y_{\text {new position }}(t-1)+\operatorname{Velocity}_{i}(t),
\end{aligned}
$$

where "ar" represents the atlas and range operator.

In each generation, total number of Rock Dove will be reduced to semi Numberpopulation during the phase of familiar sight operator and the Rock Dove, which possess the poor fitness value, which occupies the lower half will be abandoned. Since it is to be assumed that those Rock Dove are unfamiliar with familiar sights and very far from the reaching place. Few Rock Dove will be at center of the iteration and symbolized as $Y_{c}(t)$ and each rock dove can fly towards the final target place. The position of the Rock Dove is computed by

$$
\begin{gathered}
\text { Number }{ }_{\text {population }}=\frac{\text { Number }_{\text {population }}(t-1)}{2} \\
Y_{c}(t)=\frac{\sum Y_{\text {new position }} \cdot \text { fitness }\left(Y_{\text {new position }}(t)\right)}{\text { Number }} \text { population } \sum \text { fitness }\left(Y_{\text {new position }}(t)\right) \\
Y_{\text {new position }}(t)=Y_{\text {new position }}(t-1)+ \\
+ \text { random } \cdot\left(Y_{c}(t)-Y_{\text {new position }}(t-1)\right) .
\end{gathered}
$$

Individual Rock Dove fitness value is computed by

$$
f\left(Y_{\text {new position }}(t)\right)=\frac{1}{f\left(Y_{\text {new position }}(t)\right)+\varepsilon} .
$$

With respect to memory space Rock Dove memory allocated as follows:

$$
\begin{gathered}
\text { Rock Dove Memory }= \\
=\left[\begin{array}{ccc}
Y_{1}(1) & \cdots & Y_{1}(N) \\
\vdots & \ddots & \vdots \\
Y_{R D}(1) & \cdots & Y_{R D}(N)
\end{array}\right]\left[\begin{array}{c}
f\left(Y_{1}\right) \\
\ldots \\
f\left(Y_{R D}\right)
\end{array}\right] .
\end{gathered}
$$

The fitness cost function is computed with respect to the penalty function by

$$
\text { Fitness }(\text { solution })=\sum_{i=1}^{n} R D_{i} s[i] \times \text { penalty }[i] .
$$

The following consequence is applied:

1) start;

2) initialization of parameters;

3) engender the population of Rock Dove;

4) velocity and path of each Rock Dove generated;

5) each Rock Dove fitness value is computed;

6) for obtaining a global path, comparison is done between individual Rock Dove fitness;

7) while $t \leq t_{1}$ maximum do;

8) apply the atlas and range operator;

9) velocity and path of each Rock Dove are updated;

10) the global best path updated;

11) end while; 
12) while $t \leq t_{2}$ maximum do;

13) apply the familiar sight operator;

14) with respect to the fitness value sort the Rock Dove;

15) Rock Dove with low fitness value will follow the high fitness value possessed Rock Dove (12);

16) center of Rock Dove is founded (13);

17) fly directions of Rock Dove are assigned (14);

18) best Rock Dove parameters are memorized;

19) the best fitness value of Rock Dove is saved in memory;

20) end while;

21) end.

\subsection{Fuligo Septica Optimization Algorithm}

In this work, Fuligo Septica Optimization (FSO) algorithm is designed for real power loss reduction. The natural vacillation mode of Fuligo Septica has been imitated to design the algorithm. Fuligo Septica connects the food through swinging action and posses exploration and exploitation capabilities. Fuligo Septica naturally lives in chilly and moist conditions. Mainly the organic matter in the Fuligo Septica will search for the food, and enzymes formed will digest the food. In the movement of Fuligo Septica it will spread like a venous network and cytoplasm will flow inside the Fuligo Septica in all ends. The major advantage of the Fuligo Septica spreading venous like structure is multiple ways it can access the food. When the vein of Fuligo Septica moves towards the food source, the bio-oscillator engender a propagating wave that augments cytoplasmic flow in the vein, enhancing vein thickness. The amalgamation of positive and negative feedback, the Fuligo Septica put up an optimal path to unite food in a better-quality manner. The venous composition of Fuligo Septica expands along with the segment differentiation of the retrenchment mode. Consequently, there are three associations among the morphological alteration of the venous arrangement and the retrenchment method of Fuligo Septica. Solid veins generally form beside the radius when the retrenchment frequencies diverge from exterior to within. Once the retrenchment mode is unbalanced, anisotropy commences materializing. Once the retrenchment model of Fuligo Septica is not prearranged with time and space, then the venous formation will not exist. Consequently, the association between venous formation and retrenchment model of Fuligo Septica is constant with the outline of in nature produced cells. The depth of each vein is defined by the flow feedback of the cytoplasm. Veins diameter increased by the flow of cytoplasm. When flow decrease, the veins diameter decreases. When the food concentration is high then Fuligo Septica will grow stronger and stronger. Exactly with respect to the food concentration, Fuligo Septica will adjust its movement. Depend upon the availability of food sources, Fuligo Septica will dynamically adjust the search patterns.

With respect to the smell of the air, Fuligo Septica will approach the food, and it expressed with retrenchment mode by:

$$
\overrightarrow{Y(t+1)}=\left\{\begin{array}{c}
\overrightarrow{Y_{b}(t)}+\overrightarrow{G b} \cdot\left(\vec{H} \cdot \overrightarrow{Y_{A}(t)}-\overrightarrow{Y_{B}(t)}, r<p\right) \\
\overrightarrow{G_{c}} \cdot \overrightarrow{Y(t)}, r \geq p .
\end{array}\right.
$$

Where $\overrightarrow{Y_{A}}$ and $\overrightarrow{Y_{B}}$ are arbitrarily selected individuals:

$$
\begin{gathered}
p=\tanh \mid \text { Fitness }(i)-\text { Best Fitness } \mid ; \\
a \overrightarrow{G b}=[-a, a] ; \\
\quad \overrightarrow{\text { value of Smell } \text { index }(H(l))}= \\
=\left\{\begin{array}{c}
1+r \cdot \log \left(\frac{\text { Best fitness }-S(i)}{\text { Best fitness }- \text { worst fitness }}+1\right) \\
\text { unique condition } \\
\left.1-r \cdot \log \left(\frac{\text { Burrent iteration }}{\text { maximum_iteration }}\right)+1\right) ; \\
\text { Best fitness }-S(i) \\
\text { remaining }- \text { worst fitness }
\end{array}\right) ;
\end{gathered}
$$

value of Smell index $=\operatorname{sort}(S)$.

Location of the Fuligo Septica is updated by

$$
=\left\{\begin{array}{c}
\overrightarrow{Y^{*}}= \\
\text { random. (Upper bound }- \text { Lower bound })+ \text { Lower bound, random }<Z ; \\
\overrightarrow{Y_{b}(t)}+\overrightarrow{G b} \cdot\left(\vec{H} \cdot \overrightarrow{Y_{A}(t)}-\overrightarrow{Y_{B}(t)}, r<p\right) ; \\
\overrightarrow{G_{c}} \cdot \overrightarrow{Y(t)}, \quad r \geq p .
\end{array}\right.
$$

Both $\overrightarrow{G_{b}}$ and $\overrightarrow{G_{c}}$ imitate the natural behavior of the Fuligo Septica. In the swinging development $\overrightarrow{G_{b}}$ kindle the state of the Fuligo Septica about the decision to be with the particular food source or to find another higher concentration food source.

The following consequence is applied:

1) start;

2) initialization of parameters;

3) engender the population of Fuligo Septica;

4) position of Fuligo Septica is initialized;

5) $Y_{i}(i=1,2, \ldots, n)$;

6) while (current iteration $(t) \leq$ amx_iteration);

7) the fitness value of each Fuligo Septica computed;

8) update the best fitness value;

9) compute the oscillation frequency of Fuligo Septica (22):

10) for every explores segment to update the values $p, g b, g c$;

11) update the position of Fuligo Septica (24);

12) end for;

13) $t=t+1$

14) end while;

15) return the best fitness.

\section{Results}

Rock Dove (RD) optimization algorithm and Fuligo Septica Optimization (FSO) algorithm evaluated in IEEE $14,30,57,118$ and 300 bus systems [18] the validity of the and comparison results are presented in Table 1 . Real power loss and percentage of real power loss reduction comparison are shown in Figure 1. 
Table 1 - Comparison of losses

\begin{tabular}{|c|c|c|c|c|c|c|c|}
\hline \multicolumn{8}{|c|}{ IEEE 14 bus system } \\
\hline Parameters & $\begin{array}{c}\text { Value of the } \\
\text { base case [19] }\end{array}$ & $\begin{array}{c}\text { Method } \\
\text { MPSO [19] }\end{array}$ & $\begin{array}{c}\text { Method PSO } \\
{[24]}\end{array}$ & $\begin{array}{c}\text { Method EP } \\
\text { [23] }\end{array}$ & $\begin{array}{c}\text { Method } \\
\text { SARGA [23] }\end{array}$ & $\mathrm{RD}$ & FSO \\
\hline $\begin{array}{l}\text { Percentage of } \\
\text { Reduction in } \\
\text { power loss }\end{array}$ & 0 & 9.2 & 9.1 & 1.5 & 2.5 & 26.12 & 26.07 \\
\hline $\begin{array}{l}\text { Power Loss } \\
\text { (MW) }\end{array}$ & 13.550 & 12.293 & 12.315 & 13.346 & 13.216 & 10.010 & 10.017 \\
\hline \multicolumn{8}{|c|}{ IEEE 30 bus system } \\
\hline Parameters & $\begin{array}{c}\text { Value of the } \\
\text { base case [19] }\end{array}$ & $\begin{array}{c}\text { Method } \\
\text { MPSO [19] }\end{array}$ & $\begin{array}{c}\text { Method PSO } \\
{[24]}\end{array}$ & $\begin{array}{c}\text { Method EP } \\
{[23]}\end{array}$ & $\begin{array}{c}\text { Method } \\
\text { SARGA [23] }\end{array}$ & $\mathrm{RD}$ & FSO \\
\hline $\begin{array}{l}\text { Percentage of } \\
\text { Reduction in } \\
\text { power loss }\end{array}$ & 0 & 8.4 & 7.4 & 6.6 & 8.3 & 18.00 & 18.29 \\
\hline $\begin{array}{l}\text { Power Loss } \\
\text { (MW) }\end{array}$ & 17.55 & 16.07 & 16.25 & 16.38 & 16.09 & 14.39 & 14.34 \\
\hline \multicolumn{8}{|c|}{ IEEE 57 bus system } \\
\hline Parameters & $\begin{array}{l}\text { Value of the } \\
\text { base case }\end{array}$ & $\begin{array}{c}\text { Method } \\
\text { MPSO [19] }\end{array}$ & $\begin{array}{c}\text { Method PSO } \\
{[24]}\end{array}$ & $\begin{array}{c}\text { Method CGA } \\
\text { [23] }\end{array}$ & $\begin{array}{c}\text { Method AGA } \\
{[23]}\end{array}$ & $\mathrm{RD}$ & FSO \\
\hline $\begin{array}{l}\text { Percentage of } \\
\text { Reduction in } \\
\text { power loss }\end{array}$ & 0 & 15.4 & 14.1 & 9.2 & 11.6 & 22.87 & 22.90 \\
\hline $\begin{array}{l}\text { Power Loss } \\
\text { (MW) }\end{array}$ & 27.8 & 23.51 & 23.86 & 25.24 & 24.56 & 21.441 & 21.433 \\
\hline \multicolumn{8}{|c|}{ IEEE 118 bus system } \\
\hline Parameters & $\begin{array}{c}\text { Value of the } \\
\text { base case [19] }\end{array}$ & $\begin{array}{c}\text { Method } \\
\text { MPSO [19] }\end{array}$ & $\begin{array}{c}\text { Method PSO } \\
{[19]}\end{array}$ & $\begin{array}{l}\text { Method } \\
\text { IPSO [22] }\end{array}$ & $\begin{array}{c}\text { Method } \\
\text { CLPSO [22] }\end{array}$ & $\mathrm{RD}$ & FSO \\
\hline $\begin{array}{l}\text { Percentage of } \\
\text { Reduction in } \\
\text { power loss }\end{array}$ & 0 & 11.7 & 10.1 & 0.6 & 1.3 & 13.32 & 13.39 \\
\hline $\begin{array}{l}\text { Power Loss } \\
\text { (MW) }\end{array}$ & 132.8 & 117.19 & 119.34 & 131.99 & 130.96 & 115.10 & 115.01 \\
\hline \multicolumn{8}{|c|}{ IEEE 300 bus system } \\
\hline Parameter & EGA [21] & FEA [21] & CSA [20] & $\mathrm{RD}$ & FSO & - & - \\
\hline $\begin{array}{l}\text { Power Loss } \\
\text { (MW) }\end{array}$ & 646.2998 & 650.6027 & 635.8942 & 612.0914 & 612.0099 & - & - \\
\hline
\end{tabular}

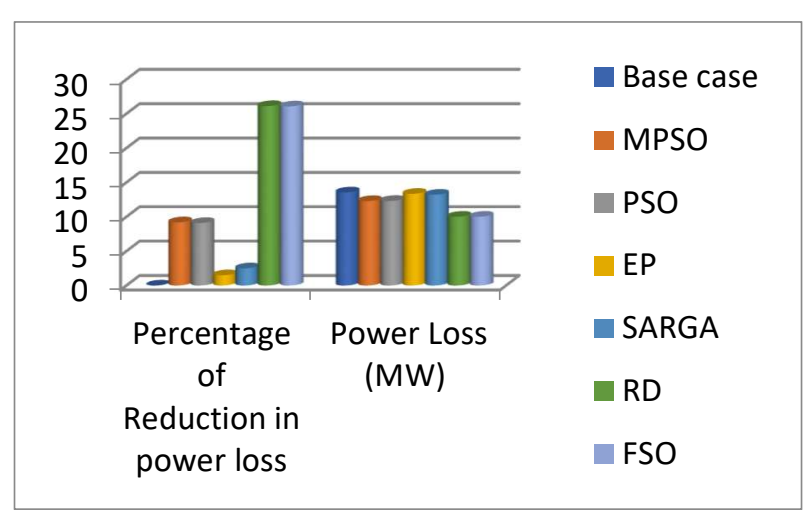

a

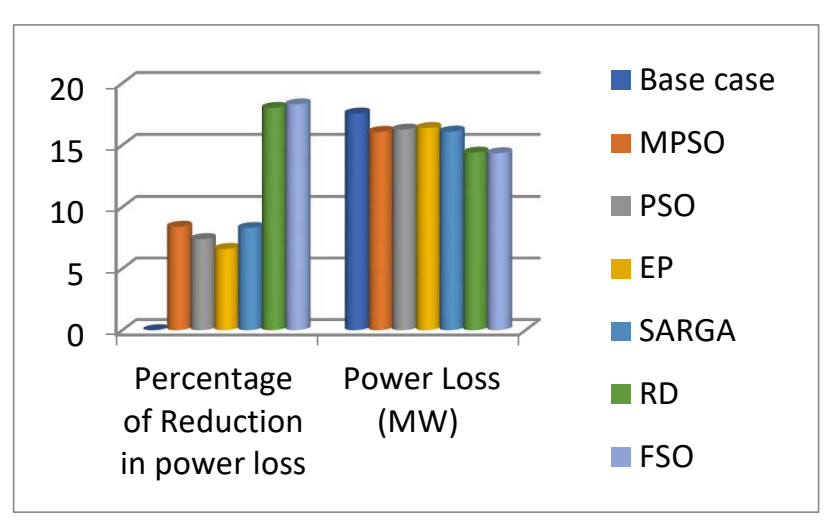

b 

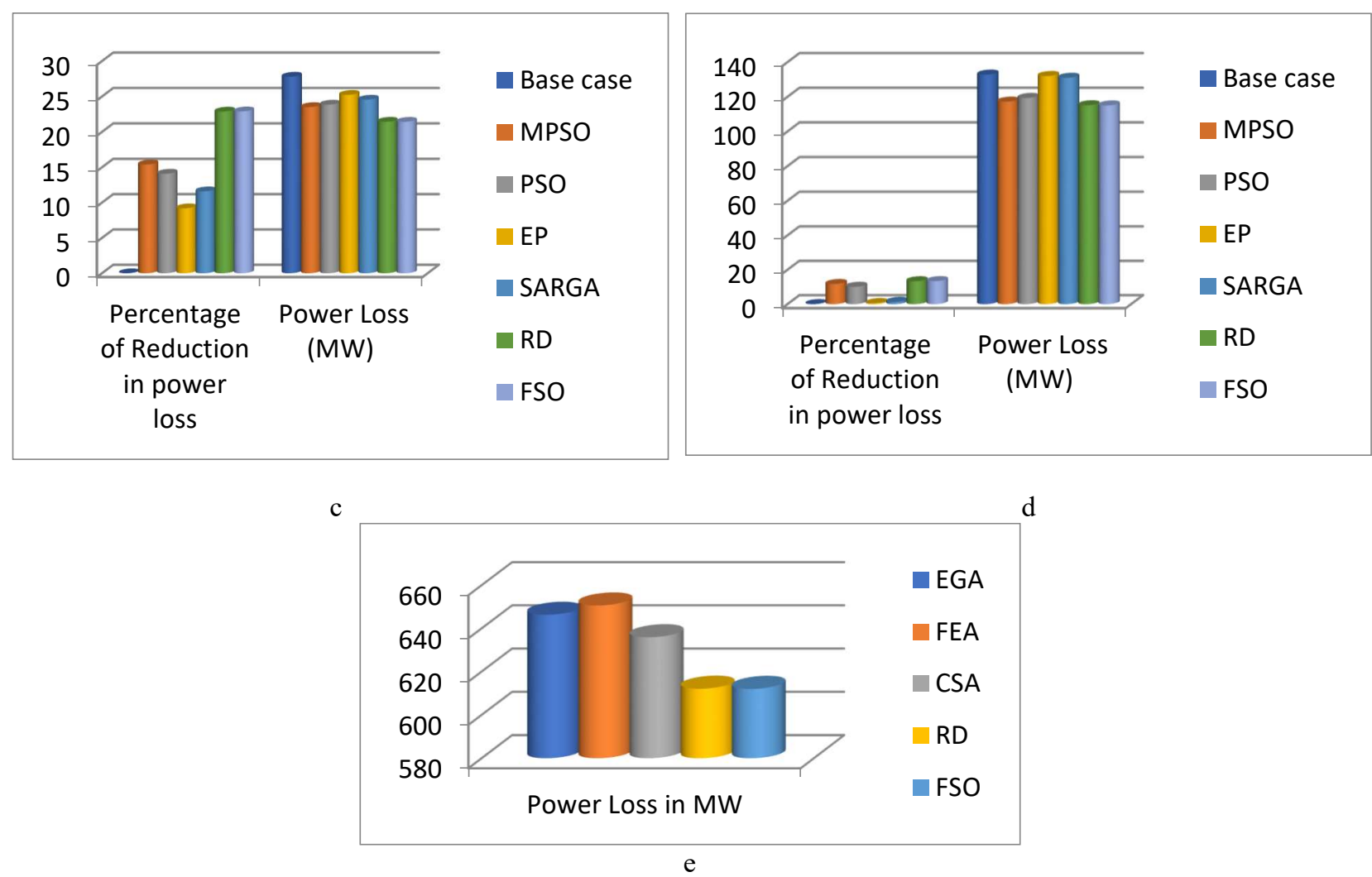

Figure 1 - Comparison of power losses: IEEE14 bus system (a); IEEE 30 bus system (b); IEEE 57 bus system (c); IEEE 118 bus system (d); IEEE 300 bus system (e)

\section{Conclusions}

In this paper, Rock Dove (RD) optimization algorithm and Fuligo Septica Optimization (FSO) algorithm have been successfully real power loss. In RD algorithm Rock Dove moves towards the global best path by the evaluation of the paths. The procedure for discovering the solution space is repetitive until the utmost iterations are reached. Based on their fitness value center of the Rock Dove raking is done. The lowest fitness value possessed Rock Dove will move towards those Rock Dove, which has the highest fitness values. Only some Rock Dove will be at center of the iteration, and each Rock Dove can fly towards the final target place. In FSO algorithm, solid veins generally form beside the radius when the retrenchment frequencies diverge from exterior to within.
Once the retrenchment mode is unbalanced, anisotropy commences materializing. Once the retrenchment model of Fuligo Septica is not prearranged with time and space, then the venous formation will not exist. The veins diameter increased by the flow of cytoplasm. When flow decrease, the veins diameter decreases. When the food concentration is high, then Fuligo Septica will grow stronger and stronger. Exactly with respect to the food concentration, Fuligo Septica will adjust its movement. Depend upon the availability of food sources, Fuligo Septica will dynamically adjust the search patterns. Proposed Rock Dove (RD) optimization algorithm and Fuligo Septica Optimization (FSO) algorithm has been tested in standard IEEE 14, 30, 57, 118 and 300 bus test systems and simulation results show the projected RD and FSO algorithm's reduced the real power loss.

\section{References}

1. Lee, K. Y. (1984). Fuel-cost minimisation for both real and reactive-power dispatches. Proceedings Generation, Transmission and Distribution Conference. Vol. 131(3), pp. 85-93.

2. Deeb, N. I. (1998). An efficient technique for reactive power dispatch using a revised linear programming approach. Electric Power System Research. Vol. 15(2), pp. 121-134.

3. Bjelogrlic, M. R., Calovic, M. S., Babic, B. S. (1990). Application of Newton's optimal power flow in voltage/reactive power control. IEEE Trans Power System, Vol. 5(4), pp. 1447-1454.

4. Granville, S. (1994). Optimal reactive dispatch through interior point methods. IEEE Transactions on Power System. Vol. 9(1), pp. 136-146, doi: 10.1109/59.317548.

5. N. Grudinin.(1998). "Reactive power optimization using successive quadratic programming method," IEEE Transactions on Power System, vol/issue: 13(4), pp. 1219-1225. http://dx.doi.org/10.1109/59.736232. 
6. Ng, R., Sulaiman, M. H., Mustaffa, Z., Daniyal, H. (2017). Optimal reactive power dispatch solution by loss minimization using moth-flame optimization technique. Appl. Soft Comput., Vol. 59, pp. 210-222.

7. Chen, G., Liu, L., Zhang, Z., Huang, S. (2017). Optimal reactive power dispatch by improved GSA-based algorithm with the novel strategies to handle constraints. Appl. Soft Comput., Vol. 50, pp. 58-70.

8. Naderi, E., Narimani, H., Fathi, M., Narimani, M. R. (2017). A novel fuzzy adaptive configuration of particle swarm optimization to solve large-scale optimal reactive power dispatch. Appl. Soft Comput., Vol. 53, pp. 441-456.

9. Heidari, A. A., Ali Abbaspour, R., Jordehi, R. (2017). Gaussian bare-bones water cycle algorithm for optimal reactive power dispatch in electrical power systems. Appl. Soft Comput., Vol. 57, pp. 657-671.

10. Morgan, M., Abdullah, N. R. H., Sulaiman, M. H., Mustafa, M., Samad, R. (2016). Benchmark studies on optimal reactive power dispatch (ORPD) based multi-objective evolutionary programming (MOEP) using mutation based on adaptive mutation adapter (AMO) and polynomial mutation operator (PMO). Journal of Electrical Systems, Vol. 12(1), pp. 121-132.

11. Ng, R., Sulaiman, M. H., Mustaffa, Z. (2016). Ant lion optimizer for optimal reactive power dispatch solution. Journal of Electrical Systems, Special Issue “AMPE2015”, pp. 68-74.

12. Anbarasan, P., Jayabarathi, T. (2017). Optimal reactive power dispatch problem solved by symbiotic organism search algorithm. 2017 Innovations in Power and Advanced Computing Technologies (i-PACT), pp. 1-8, doi: 10.1109/IPACT.2017.8244970.

13. Gagliano, A., Nocera, F. (2017). Analysis of the performances of electric energy storage in residential applications. International Journal of Heat and Technology, Vol. 35(1), pp. S41-S48, doi: 10.18280/ijht.35Sp0106.

14. Caldera, M., Ungaro, P., Cammarata, G., Puglisi, G. (2018). Survey-based analysis of the electrical energy demand in Italian households. Mathematical Modelling of Engineering Problems, Vol. 5(3), pp. 217-224, doi: 10.18280/mmep.050313.

15. Basu, M. (2016). Quasi-oppositional differential evolution for optimal reactive power dispatch. Electrical Power and Energy Systems, Vol. 78, pp. 29-40.

16. Weise, T. (2009). Global Optimization Algorithms - Theory and Application. Retrieved at: http://www.it-weise.de.

17. Mirjalili, S., Lewis, A. (2016). The whale optimization algorithm. Advanced Engineering Software, Vol. 95, pp. 51-67.

18. IEEE (1993). The IEEE-Test Systems. Retrieved at: http://www.ee.washington.edu/trsearch/pstca.

19. Hussain, A. N., Abdullah, A. A., Neda, O. M. (2018). Modified Particle swarm optimization for solution of reactive power dispatch. Research Journal of Applied Sciences, Engineering and Technology, Vol. 15(8), pp. 316-327, doi: 10.19026/rjaset.15.5917.

20. Reddy, S. S. (2017). Optimal reactive power scheduling using cuckoo search algorithm. International Journal of Electrical and Computer Engineering, Vol. 7(5), pp. 2349-2356.

21. Reddy, S. S., et al. (2014). Faster evolutionary algorithm based optimal power flow using incremental variables. Electrical Power and Energy Systems, Vol. 54, pp. 198-210.

22. Dai, C., Chen, W., Zhu, Y., Zhang, X. (2009). Seeker optimization algorithm for optimal reactive power dispatch. IEEE T. Power Syst., Vol. 24(3), pp. 1218-1231.

23. Subbaraj, P., Rajnarayan, P. N. (2009). Optimal reactive power dispatch using self-adaptive real coded genetic algorithm. Electr. Power Syst. Res., Vol. 79(2), pp. 374-381.

24. Pandya, S., Roy, R. (2015). Particle swarm optimization based optimal reactive power dispatch. Proceeding of the IEEE International Conference on Electrical, Computer and Communication Technologies (ICECCT), pp. 1-5. 